\title{
EFFECT OF LONGITUDINAL REINFORCEMENT RATIO ON THE SHEAR BEHAVIOR OF RC BEAMS MADE WITH RECYCLED AGGREGATES
}

\author{
Nariman J. Khalil ${ }^{1}$, Roger Makhoul ${ }^{2}$ \\ ${ }^{1}$ Associate Professor, Department of Civil Engineering, University of Balamand, Koura- \\ Lebanon \\ e-mail: nariman.khalil@balamand.edu.lb \\ ${ }^{2}$ Graduate Student, Department of Civil engineering, University of Balamand, Koura- \\ Lebanon
}

\begin{abstract}
This paper presents a study into the effect of longitudinal reinforcement ratio on the shear behavior of Recycled Aggregates Concrete beams (RAC). Six beams were cast in two series: first series includes three beams with $\rho=1.04 \%$ and the second series includes three beams with $\rho=1.5 \%$. The first beam of each series was cast with natural coarse aggregates (R0) to serve as control beam. The second beam was made with $50 \%$ replacement ratio of coarse aggregates (R50) and the third beam was made entirely with recycled concrete aggregates (R100). The shear span was constant for all beams $\mathrm{a} / \mathrm{d}=3.5$. The beams were subjected to four point loading test. Beams' deflection, crack patterns, yielding, ultimate shear capacity; and failure modes are all observed and analyzed. Significant increase in the shear strength was recorded as longitudinal reinforcement ratio increases by $0.5 \%$. ACI Code provisions for predicting the concrete shear capacity tends to become more conservative with increasing $\rho$.
\end{abstract}

Keywords: Reinforcement ratio, shear behavior, reinforced concrete, recycled aggregates, shear span

\section{INTRODUCTION}

Several studies have been conducted on utilizing recycled aggregate concrete as a structural material. Research focused mostly on the mechanical properties and expanded to cover members subjected to flexure and shear. However, the work on shear still limited. Shear behavior of reinforced concrete beams is a very complex phenomenon as it is influenced by many factors such as the member size, concrete compressive strength, shear span to depth ratio and presence or absence of web reinforcement. Etxeberria et al (2007) studied twelve beam specimens with same compressive strength, constant longitudinal reinforcement ratio and constant shear span to depth ratio. Four concrete mixes using different percentages of recycled coarse aggregates were used $(0 \%, 25 \%, 50 \%$ and $100 \%)$ and three different transverse 
reinforcement arrangements. Results obtained indicated that the $25 \%$ substitution of coarse aggregates has negligible effects on the shear capacity of RC beams without transverse reinforcement. Beams with shear reinforcement and modified cement content achieved approximately the ultimate shear load of conventional concrete even with $100 \%$ replacement ratio. Fonteboa et al (2010) examined the behavior of recycled concrete in response to the phenomenon of shear transfer. Double-L shear specimens were designed using two types of concrete, a conventional and a recycled concrete, both made with $8 \%$ of silica fume. Without shear reinforcement, the shear friction capacity of recycled concrete with $50 \%$ replacement ratio suffers a decrease of $20 \%$. When using any quantity of steel, this loss comes down to $10-15 \%$. The use of silica fume led to a substantial rise in the ultimate load of recycled concrete. Fathifazl et al (2011) investigated the effects of shear span to depth ratio and beam size on the shear strength of RAC beams. They concluded that the shear strength of RAC beams had tendency to increase with decreasing a/d ratio and tendency to increase with decrease in the overall depth of the beams. Arezoumandi et al (2015) tested 18 beams with three different longitudinal reinforcement ratios: 1.3, 2.0, and $2.7 \%$. results showed that $\mathrm{RAC} 100$ had $11 \%$ lower shear strength on average compared with the RAC50 and CC beams. Rahal K. N., and Alrefaei Y.T. (2018) tested a total of 18 beams. The variables were the percentage of replacement of natural coarse aggregates with RCA in concrete mixes and the amount of stirrups provided. The longitudinal reinforcement ratio in all the beams was $1.38 \%$. the results showed negligible effects of the replacement ratio on shear cracking patterns, the critical shear cracks, the longitudinal steel strains and the mode of failure.

Based on literature, work comparing the effect of the longitudinal steel ratio on the shear strength is limited. In this paper, two percentage of steel were considered using full-scale shear testing of RAC beams.

\section{EXPERIMENTAL PROGRAM}

\section{Test Beam Design}

Two series of beams were designed to fail in shear. All beams had the same cross section 150 by $300 \mathrm{~mm}$ and were $3 \mathrm{~m}$ long. Shear reinforcement in the form of vertical stirrups was omitted. The first series was reinforced with $2 \mathrm{~T} 16$ bars in tension giving reinforcement ratio $\rho$ of $1.04 \%$ while the second series had 2 T 20 in tension giving $\rho=1.5 \%$. In each series, the first beam was made fully with natural aggregates, the second beam was made with $50 \%$ replacement ratio of coarse aggregates with recycled concrete aggregates. The third beam was fully made with recycled concrete aggregates. Figure 1 shows beams cross sections.
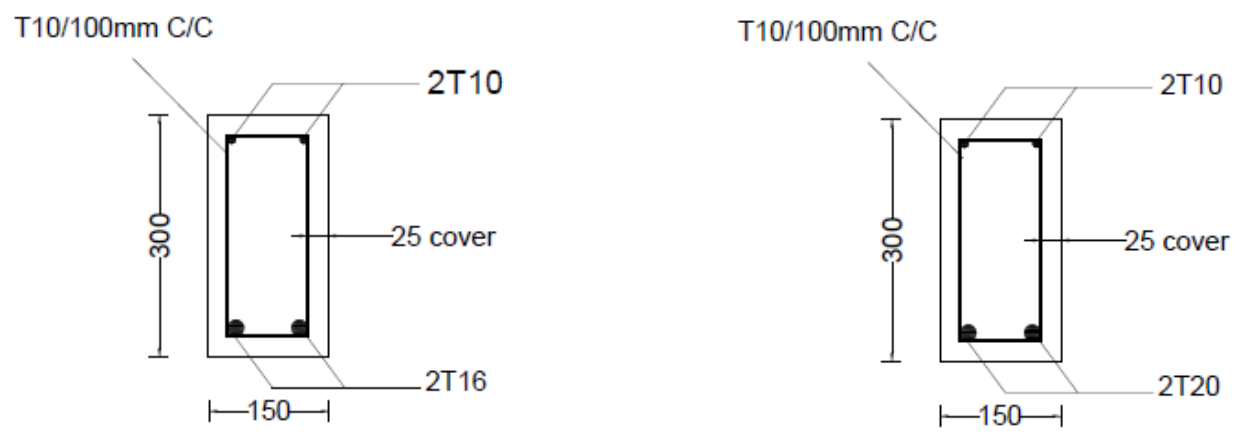

(a) Series I
(b) Series II

\section{Materials and Mix Proportions}

Figure 1: Beams cross-section

The recycled concrete aggregates were obtained by crushing the control specimens tested at UOB civil engineering laboratory. All coarse aggregates were sieved into two sizes: coarse $(9.5-19 \mathrm{~mm})$ and medium $(4.75-9.5 \mathrm{~mm})$. Table 1 summarizes the test results on the physical properties of natural and recycled aggregates.

Table 1-Physical properties of natural and recycled aggregates.

\begin{tabular}{|c|c|c|c|c|}
\hline Aggregates & $\begin{array}{c}\text { NCA } \\
(4.75-9.5) \\
\mathrm{mm}\end{array}$ & $\begin{array}{c}\text { RCA } \\
(4.75-9.5) \\
\mathrm{mm}\end{array}$ & $\begin{array}{c}\text { NCA } \\
(9.5-19) \\
\mathrm{mm}\end{array}$ & $\begin{array}{c}\text { RCA } \\
(9.5-19) \\
\mathrm{mm}\end{array}$ \\
\hline $\begin{array}{c}\text { SSD (Saturated } \\
\text { Surface Dry) }\end{array}$ & 2.6536 & 2.4149 & 2.6755 & 2.2896 \\
\hline Apparent SG & 2.706 & 2.6883 & 2.7134 & 2.4566 \\
\hline $\begin{array}{c}\text { OD (Oven-Dry) } \\
\text { SG }\end{array}$ & 2.6228 & 2.2529 & 2.6533 & 2.1749 \\
\hline Absorption (\%) & 1.1713 & 7.1893 & 0.835 & 5.2725 \\
\hline Bulk density $\mathrm{kg} / \mathrm{m}^{3}$ & 1525 & 1305 & 1552 & 1359 \\
\hline
\end{tabular}

Table 2 illustrates the mix design used throughout this study. The level of coarse aggregates replacement was the only variable in the three mixes used. All constituent materials were oven dried for 24 hours at $110 \pm 5^{\circ} \mathrm{C}$. The water compensation method was used.

Table 2-Mix design

\begin{tabular}{|c|c|c|c|c|c|c|c|c|}
\hline Mix & $\begin{array}{c}\text { Cement } \\
\left(\mathrm{kg} / \mathrm{m}^{3}\right)\end{array}$ & $\begin{array}{c}\text { NCA } \\
4.75-9.5 \\
\mathrm{~mm} \\
\left(\mathrm{~kg} / \mathrm{m}^{3}\right)\end{array}$ & $\begin{array}{c}4.75-9.5 \\
\mathrm{~mm} \\
\left(\mathrm{~kg} / \mathrm{m}^{3}\right)\end{array}$ & $\begin{array}{c}\text { RCA } \\
4.75-9.5 \\
\mathrm{~mm} \\
\left(\mathrm{~kg} / \mathrm{m}^{3}\right)\end{array}$ & $\begin{array}{c}\text { RCA } \\
4.75-9.5 \\
\mathrm{~mm} \\
\left(\mathrm{~kg} / \mathrm{m}^{3}\right)\end{array}$ & $\begin{array}{c}\text { Natural } \\
\text { sand } \\
\left(\mathrm{kg} / \mathrm{m}^{3}\right)\end{array}$ & $\begin{array}{c}\text { Free } \\
\text { water } \\
\left(\mathrm{kg} / \mathrm{m}^{3}\right)\end{array}$ & $\begin{array}{c}\text { Super- } \\
\text { plasticizer } \\
\left(\mathrm{L} / \mathrm{m}^{3}\right)\end{array}$ \\
\hline R0 & 350 & 444 & 666 & 0 & 0 & 741 & 178 & 3.12 \\
\hline R50 & 350 & 222 & 333 & 202 & 285 & 741 & 178 & 3.46 \\
\hline R100 & 350 & 0 & 0 & 404 & 569.94 & 741 & 178 & 3.64 \\
\hline
\end{tabular}

All beams and the corresponding control specimens were cured for seven days; and then left for air curing in the laboratory. Beams were tested at the age of 28 days.

\section{Instrumentation and Test Setup}

To record steel and concrete strains during testing, strain gauges were attached to the main steel at three locations and on concrete on two locations as shown in Figure 2. The figure also shows the location of LVDT's for deflection measurements. The 
beams were subjected to four point loading and the load was applied at a rate of 0.01 $\mathrm{mm} / \mathrm{sec}$.

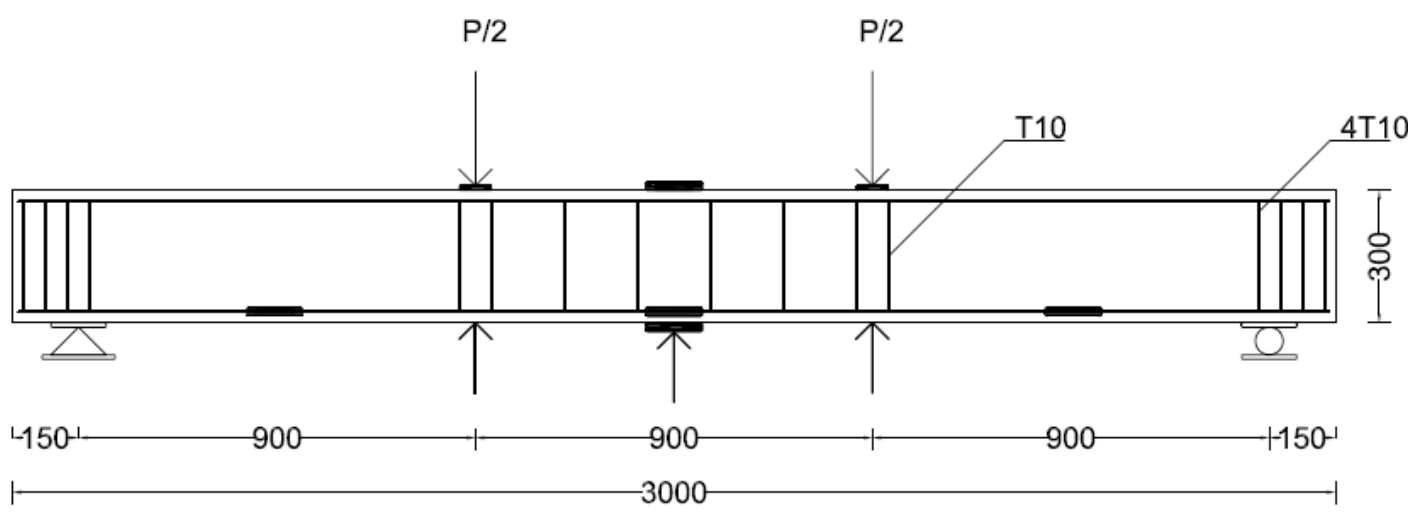

$\uparrow_{\text {LVDT }}$

— strain gauge $\quad$ Figure 2: Test set-up

\section{EXPERIMENTAL RESULTS AND DISCUSSION}

\section{Mechanical properties}

Twelve concrete specimens were cast with each beam to measure the following mechanical properties: concrete compressive strength at 7 and 28 days, splitting tensile strength, flexural tensile strength and the modulus of elasticity. Results are shown in Table 3 including fresh concrete properties.

Table 3: Fresh and hardened concrete properties

\begin{tabular}{|c|c|c|c|c|c|c|c|}
\hline Mix & $\begin{array}{c}\text { Immediate } \\
\text { slump } \\
(\mathrm{mm})\end{array}$ & $\begin{array}{c}\text { Air } \\
\text { content } \\
(\%)\end{array}$ & $\begin{array}{c}\text { 7-Day } \\
\text { Compressive } \\
\text { strength } \\
(\mathrm{MPa})\end{array}$ & $\begin{array}{c}\text { 28-Day } \\
\text { Compressive } \\
\text { strength } \\
(\mathrm{MPa})\end{array}$ & $\begin{array}{c}\text { Modulus } \\
\text { of } \\
\text { Elasticity } \\
(\mathrm{MPa})\end{array}$ & $\begin{array}{c}\text { Splitting } \\
\text { tensile } \\
\text { strength } \\
(\mathrm{MPa})\end{array}$ & $\begin{array}{c}\text { Flexural } \\
\text { tensile } \\
\text { strength } \\
(\mathrm{MPa})\end{array}$ \\
\hline R0 & 240 & 4.5 & 26.5 & 32.55 & 32,414 & 3.90 & 4.51 \\
\hline R50 & 175 & 3.5 & 24.32 & 37.2 & 32,494 & 3.66 & 3.59 \\
\hline R100 & 114 & 2.75 & 24.42 & 31.73 & 29,203 & 3.87 & 3.63 \\
\hline
\end{tabular}

Generally, there is a decrease in the mechanical properties as the replacement level of the coarse aggregates increases. Except for mix R50, which showed slight increase in the compressive strength. Modulus of elasticity has decreased by $10 \%$ for R100 as compared to R0. This indicates the vulnerability of RAC beams to deformations. This finding is similar to results obtained by the first author in previous work $(2016,2017$ and 2018).

\section{Load vs. Deflection}

Similar behavior was noticed for the two percentages of steel considered in terms of deflections, as shown in Figure 3. All beams showed linear behavior up to failure load with change in slope at the cracking level. Obviously, the increase in the percentage 
of longitudinal steel reduced the amount of deflections. At early stages of loading, RAC beams with R50\% and R100\% had approximately same deflection values, however, at higher loads, R50 beams attained higher defection levels.

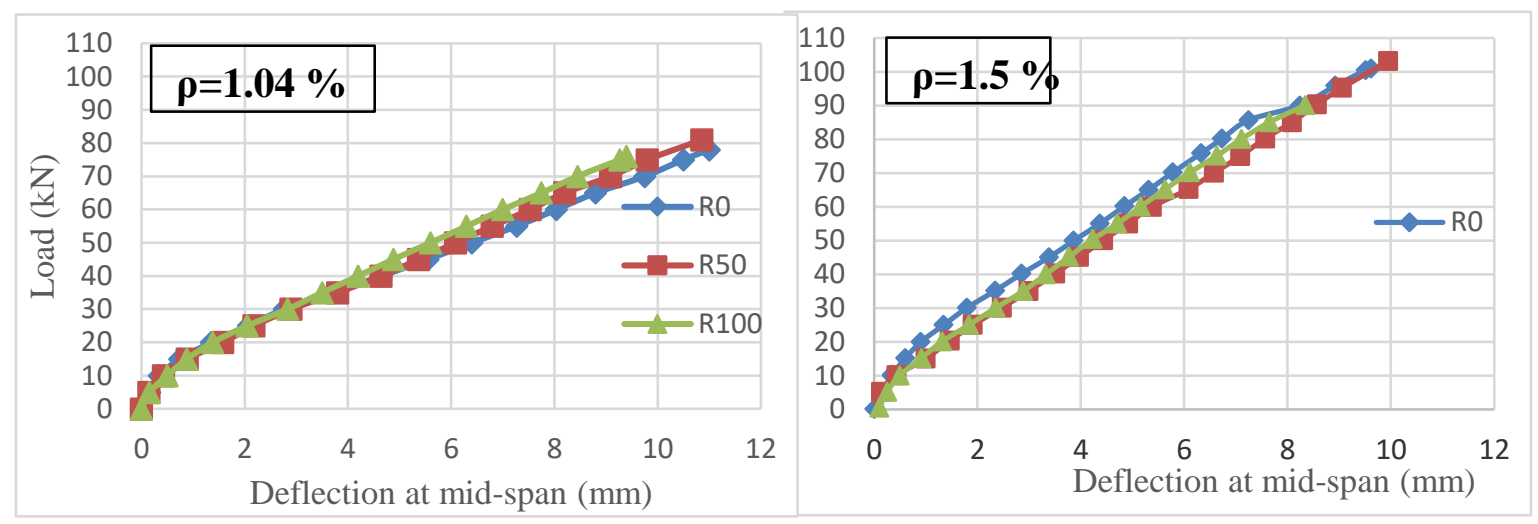

Figure 3: Mid-span deflections

Rahal et al (2018) reported maximum increase of $25 \%$ in the vertical deflections for RAC100 beams with $\rho=1.38 \%$ when compared with NAC beams (referred to as R0 in this study)

\section{Load vs. Concrete Compression Strain}

Figure 4 presents the variation of concrete compression strains against load. Comparable behavior was seen between the two series of beams. Initially all beams had the same slope till the onset of cracking. Beams with higher percentage of longitudinal steel had then higher slope as load increased to failure.

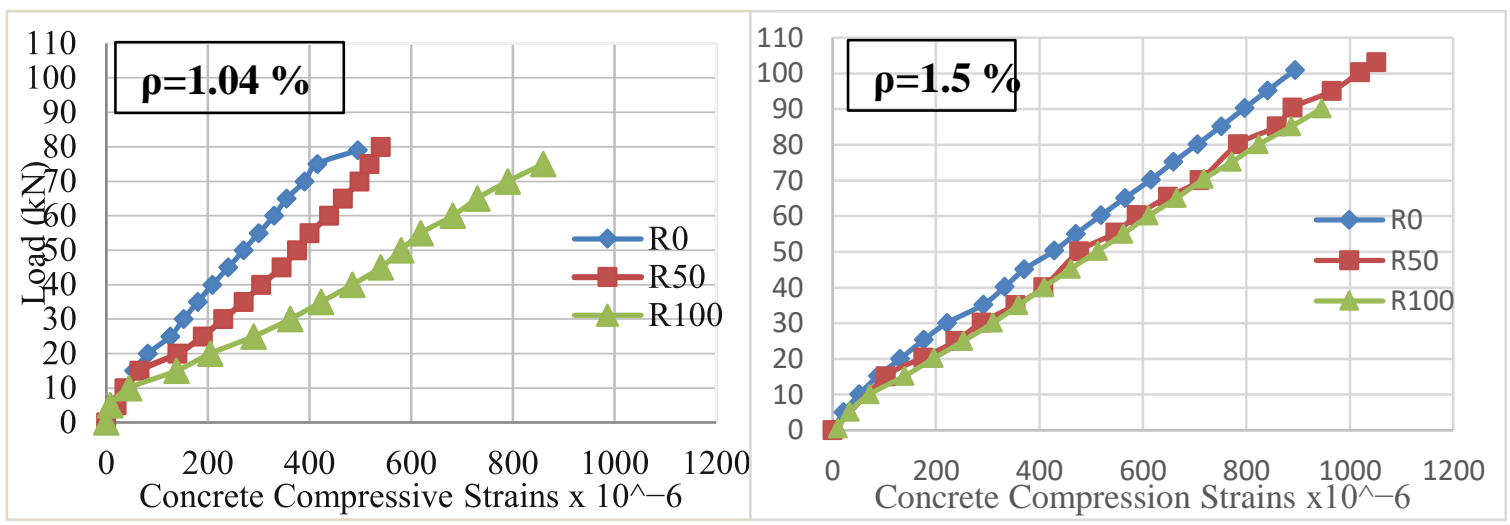

Figure 4: Concrete compressive strains at mid-span.

\section{Load vs. Steel Strain}

Variation in steel strains vs. load are presented in Figure 5. Unfortunately, a new set of strain gauges was used for R0 and R50 beams in series II. Those strain gauges 
were not compatible with the connection wires to the data acquisition system so no readings were obtained for these two beams. Data obtained for other beams indicate
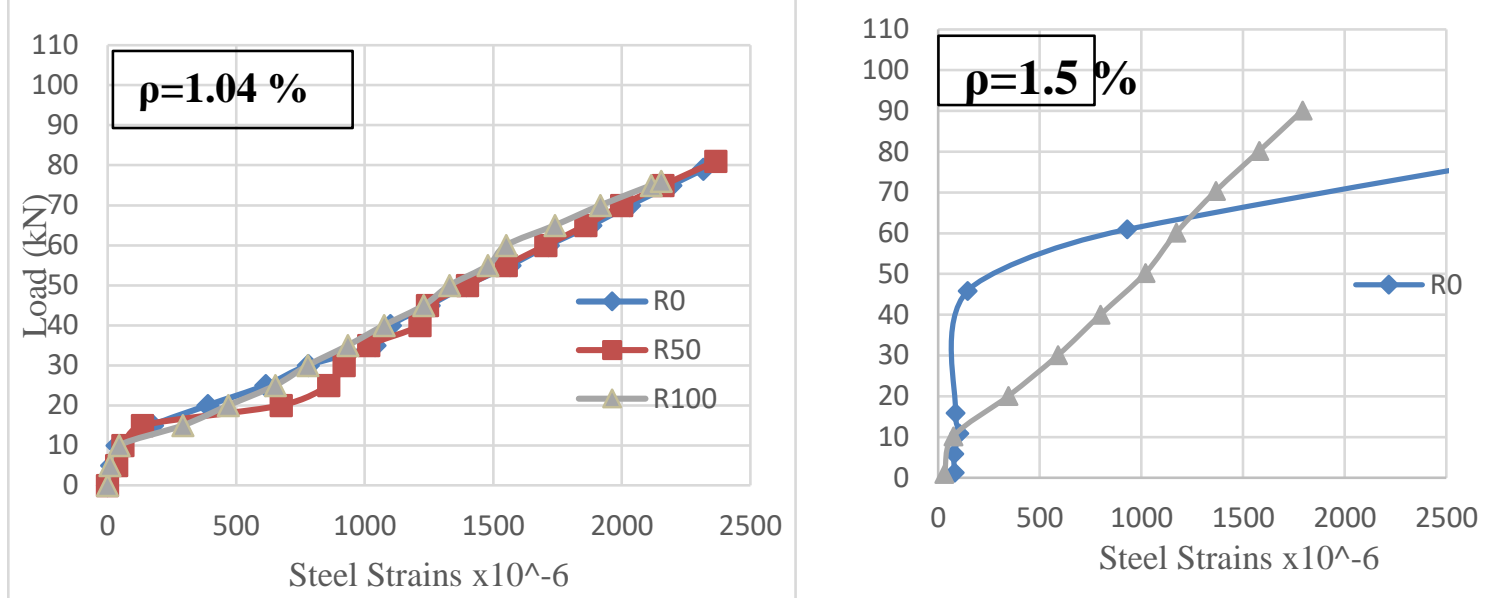

that the longitudinal steel didn't reach yielding when failure load was attained. Steel strain measurements are local measurements, hence, they are generally sensitive to the location of the gauge with respect to the nearby concrete cracks (Rahal et al 2018).

Figure 5: Load vs. steel strains at mid-span.

\section{Crack Pattern and Failure Mode}

Figure 6 illustrates the failure modes for the test beams while Figure 7 shows the cracking pattern. Cracks were initiated first in the maximum moment region at mid span, then started to get inclined towards the point loads, as the applied load was increased. A diagonal crack then formed abruptly at mid height extending from the point of load application towards the bond failure of the longitudinal steel within the shear span. This brittle shear failure was observed for all test beams. A fewer number of cracks was seen in test beams with $\rho=1.5 \%$ as compared to those with $\rho=1.04 \%$. Generally, as the percentage of recycled concrete aggregates increases, the number of cracks increases too.
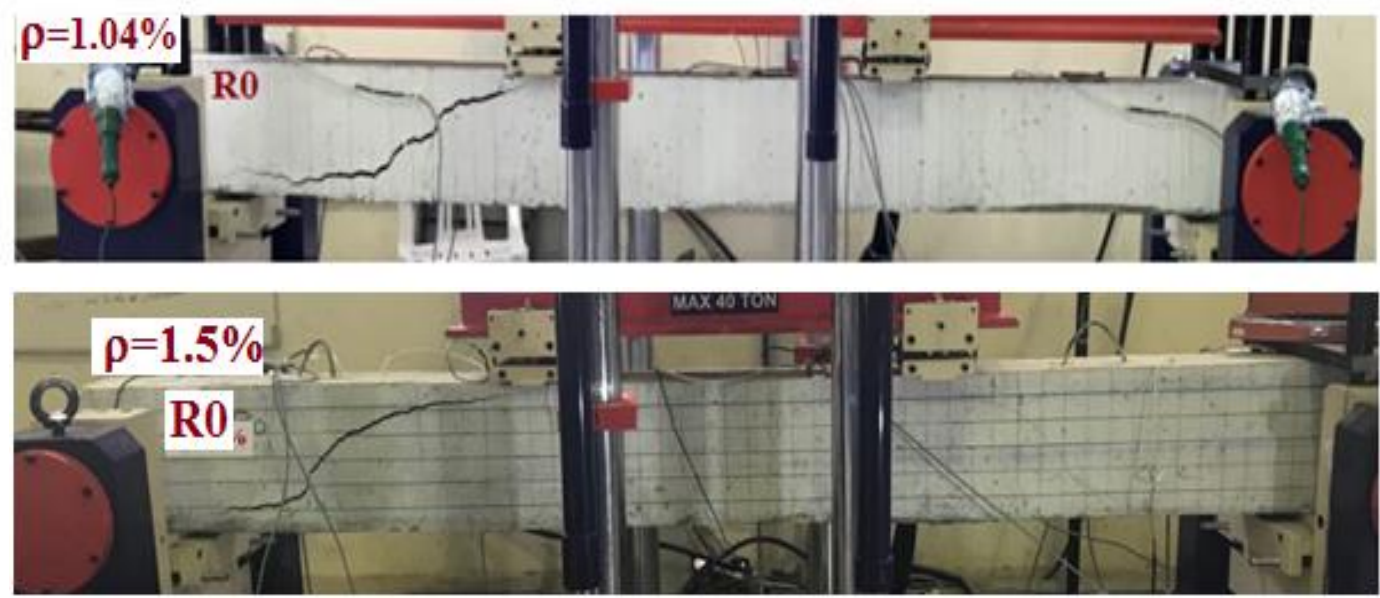

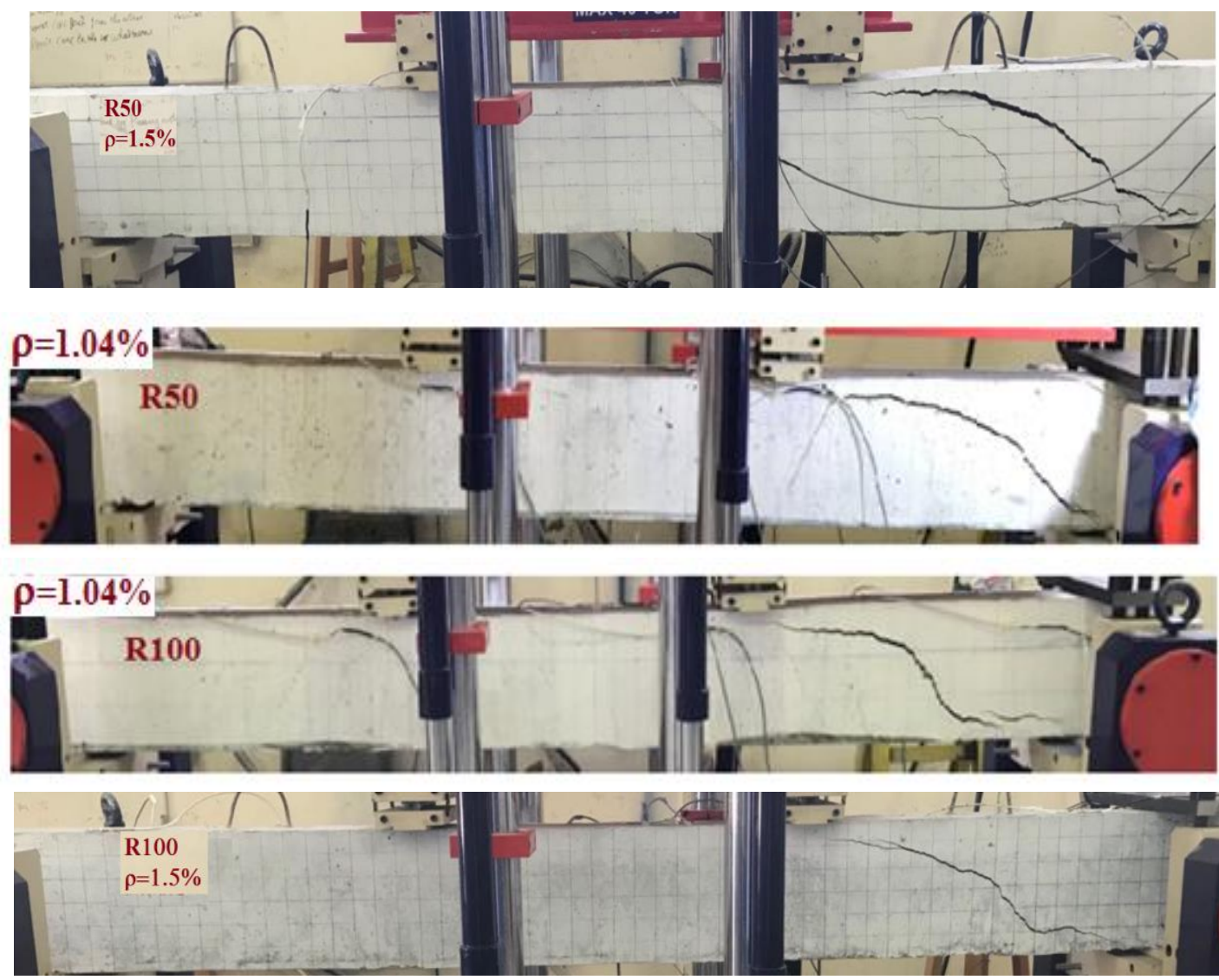

Figure 6: Failure Mode

$\rho=1.04 \%$

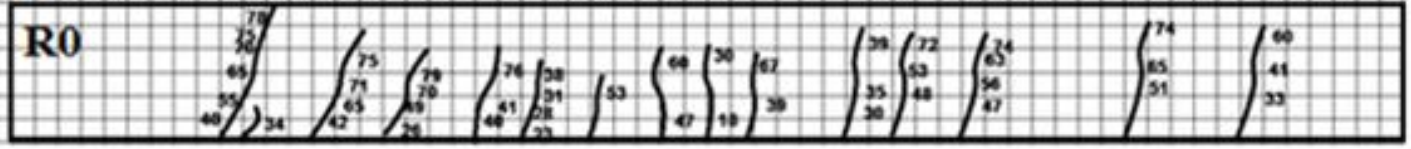

$\rho=1.5 \%$

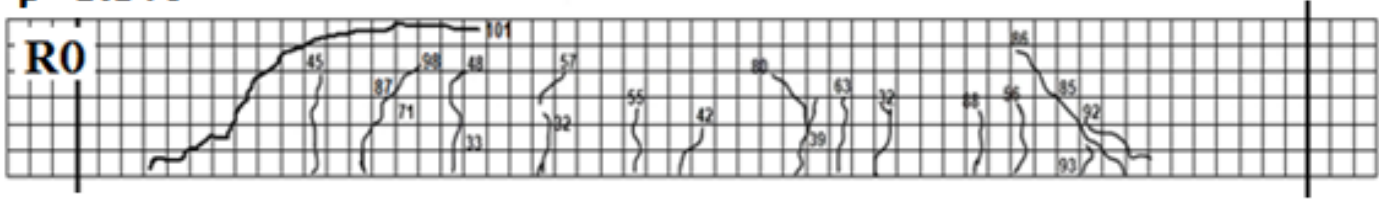

$\rho=1.04 \%$

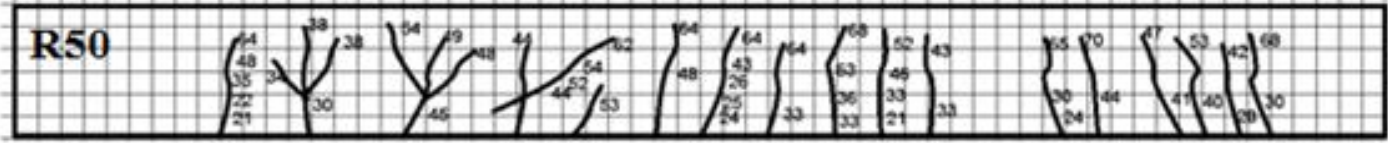

$\rho=1.5 \%$

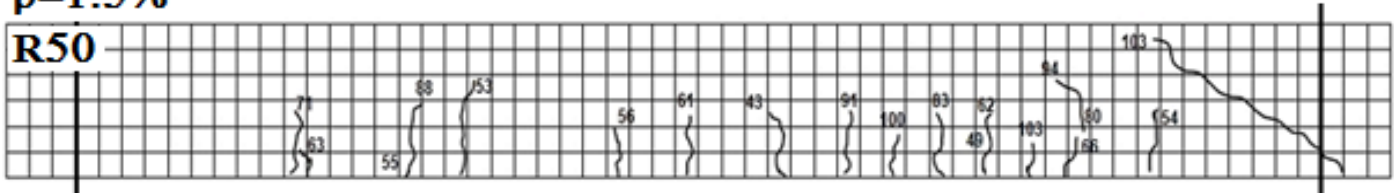




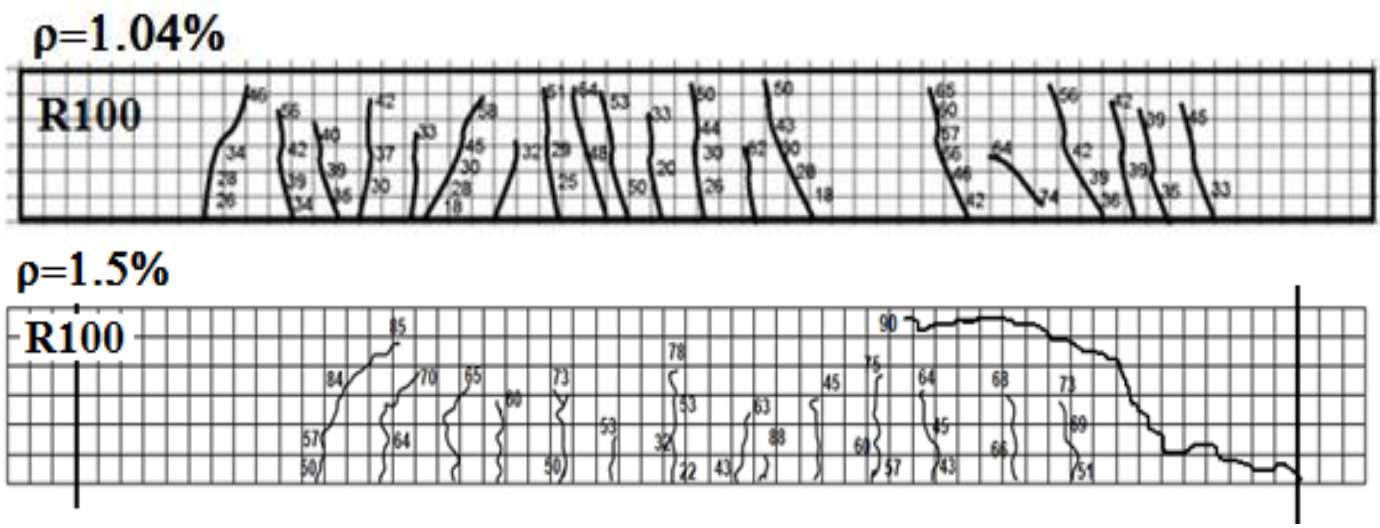

Figure 7: Crack Pattern

\section{Comparison with ACI Shear Strength}

Table 4 presents the experimental shear strength at failure $V_{\text {test }}$, for the test beams. $\mathrm{V}_{\mathrm{ACI}}$ is the shear strength predicted by ACI equation. Although ACI equation does not include the effect of the longitudinal steel; it seems that the equation gives prediction that is more conservative as $\rho$ increases. This margin of safety decreases as the percentage of recycled concrete aggregates increases. Arezoumandi et al (2015) who compared the test values of shear strength with different design standards concluded that the ratio $\left(V_{\text {test }} / V_{\text {code }}\right)$ increases for the same mix as the reinforcement ratio increases. They also stated that the $\left(V_{\text {tes }} / V_{\text {code }}\right)$ for a given standard, is lower for RCA 100 beams than for RCA 0 and RCA50 for the same $\rho$. This is in agreement with the findings of this work.

Table 4: Shear strength results

\begin{tabular}{|c|c|c|c|c|c|}
\hline \multirow{2}{*}{ Beam } & \multicolumn{2}{|c|}{$V_{\text {test }}(\mathrm{kN})$} & \multirow{2}{*}{$V_{A C I}(\mathrm{kN})$} & \multicolumn{2}{|c|}{$V_{\text {test }} / V_{A C I}$} \\
\cline { 2 - 3 } \cline { 5 - 6 } & $\rho=1.04 \%$ & $\rho=1.5 \%$ & & $\rho=1.04 \%$ & $\rho=1.5 \%$ \\
\hline R0 & 39.5 & 50.45 & 38.565 & 1.024 & 1.3 \\
\hline R50 & 40.8185 & 51.56 & 40.92 & 0.997 & 1.26 \\
\hline R100 & 38.192 & 45.07 & 40.11 & 0.952 & 1.27 \\
\hline
\end{tabular}

$\mathrm{Xu}$ et al (2012) proposed an equation for shear capacity prediction of reinforced concrete beams without stirrups using fracture mechanics approach. The proposed formula was checked against experimental data and against ACI code provisions for shear. He observed that ACI 318 overestimates the shear strength of beams, especially those with a reinforcement ratio less than $1.0 \%$. As can be seen in Table 4 , the ACI 318 Equation appears to be much more unsafe for lightly reinforced concrete beams made with recycled concrete aggregates. 


\section{CONCLUSIONS}

The following conclusions can be withdrawn:

1. In terms of mode of failure, crack pattern, load-strain and load-deflection response, the behavior of RAC100, RAC50 and RAC0 beams was similar as the longitudinal reinforcement ratio increased from 1.04 to $1.5 \%$.

2. Shear strength of beams without shear reinforcement decreases as the replacement ratio of recycled aggregates increases.

3. The increase of $0.5 \%$ in longitudinal reinforcement ratio improves the shear strength by up to $28 \%$ for R0 and R50 and $18 \%$ for R 100 .

4. Although ACI provision for shear strength prediction overestimates the shear strength of beams made with high percentage of RCA, it tends to be more conservative as the ratio of longitudinal reinforcement increases.

\section{ACKNOWLEDGMENT}

The work presented in this paper was performed at the University of Balamand.The authors would like to thank the staff of the civil engineering laboratory for their support during the experimental work.

\section{REFERENCES}

Etxeberria, M. Mari, A. R. \& Vazquez E., (2007). "Recycled aggregate concrete as structural material", Materials and Structures (2007) 40: 529-541.

Fonteboa, B. G., Martinez F., Carro D., Eiras J., (2010), "Shear friction capacity of recycled concretes", Construction Materials, Vol. 60, 299, 53-67, JulySeptember 2010.

Fathifazl, G.Razaqpur, A. G., Burkan, I. O., Abbas, A., and Fournier B., (2011)"Shear capacity evaluation of steel reinforced recycled concrete (RRC) beams, Engineering Structures 33 (2011) 1025-1033, Elsevier.

Arezoumandi M., Drury J., Volz J. S. and Khayat K. H., (2015) "Effect of recycled concrete aggregate replacement level on shear strength of reinforced concrete beams", ACI Material Journal/July-Augst 2015.

Rahal K. N., and Alrefaei Y.T., (2018), "Shear strength of recycled aggregate concrete beams containing stirrups", construction and Building Materials 191 (2018) 866-876, ELSEVIER.

Xu, S., Zhang X, and Reinhardt W., (2012). "Shear capacity prediction of reinforced concrete beams without stirrups using fracture mechanics approach” ACI Structural Journal, V. 109, No. 5, September-October 2012.

Khalil N., A. Touma, T. Touma and R. Daher, (2016) A study into the relationships between the mechanical properties of recycled aggregate concrete, Proceedings of the Second International Conference on Concrete 
Sustainability", E-Book ISBN 978-84-945077-8-6, pp 1146-1158, MadridSpain, 13-15 June, (2016).

Khalil N., Kareh A., Dahdah G., Chameddine H. and Hawshar M., (2017) “Effect of Recycled Concrete Aggregates on The Flexural Behavior of Reinforced Concrete Beams" $42^{\text {nd }}$ Conference on "Our World in Concrete \& Structures: A Sustainable and Resilient World in Concrete". ACI-Singapore Chapter, 2325 August 2017, Singapore, ISBN: 978-981-11-4234-5.

Khalil N. J., Tamer C. and Abdo F., (2018), "Shear Behavior of Reinforced Concrete Beams made with Recycled Concrete Aggregates", American Concrete Institute Special Publication, ACI SP-326-44, August 10, 2018, ISBN: 978-1-64195-022-0.

Xu, S., Zhang, X. and Reinhardt H., (2012), "Shear Capacity Prediction of Reinforced Concrete Beams without stirrups using Fracture Mechanics Approach", ACI Structural Journal, Vol. 109, No. 5 September-October 2012. 